\title{
STRATEGI PENGEMBANGAN MODEL BISNIS KOPERASI SERBA USAHA PINTO JAYA
}

\author{
STRATEGY OF BUSINESS DEVELOPMENT AT KOPERASI SERBA USAHA PINTO JAYA
}

\author{
David Andreas*), Dodik Ridho Nurrochmat ${ }^{* *}$, dan Setiadi Djohar**) \\ *) Sekolah Bisnis, IPB University \\ Jl. Padjajaran, Bogor, Indonesia 16151, Indonesia \\ ${ }^{* *)}$ Departemen Manajemen Hutan, Fakultas Kehutanan, IPB University \\ Jl. Ulin Kampus IPB Dramaga, Bogor 16680, Indonesia \\ ${ }^{* * * *}$ Sekolah Tinggi Manajemen PPM \\ Jl. Menteng Raya 9-19, Jakarta 10340, Indonesia
}

\begin{abstract}
Koperasi as an association for mutual welfare, conducts business and activities to fulfill the needs of the members. Koperasi Pinto Jaya located at Cipinang Melayu, East Jakarta, was established in 2011. The aim of this study is to design a business model in the future as a step towards further development of KSU Pinto Jaya. This research using descriptive qualitative with approaching method of business model canvas (BMC) and equipped with SWOT and blue ocean strategy. Respondents include internal and external respondents. Internal respondents are the chairman of the cooperative, supervisor, manager, head of the savings and loan unit and cooperative members with the qualifications as respondents. The external respondent is the chairman of the PT. Chingluh and Department of cooperatives and small and medium enterprises. The results obtained from this research is the idea which driven from several central innovation point, including the key activities where KSU Pinto Jaya forms a trading unit business which purposes meeting the need of the member and increasing the revenue. While the next idea as a starting point to form an innovation that starts from the addition of key resources to support and increase key activities. The official website and computer application development carried out by KSU Pinto Jaya becomes starting point to form business model ideas based on conditions where the utilization of information technology by KSU Pinto Jaya is not optimized yet.
\end{abstract}

Keywords: business model canvas, blue ocean strategy, SWOT analysis, Pinto Jaya

\begin{abstract}
Abstrak: Koperasi sebagai perkumpulan untuk kesejahteraan bersama, melakukan usaha dan kegiatan di bidang pemenuhan kebutuhan bersama dari para anggotannya. Koperasi Pinto Jaya merupakan salah satu koperasi yang berlokasi di Cipinang Melayu, Jakarta Timur, yang berdiri sejak tahun 2011. Penelitian ini bertujuan merancang model bisnis di masa depan sebagai langkah pengembangan KSU Pinto Jaya selanjutnya. Jenis penelitian yang digunakan adalah deskriptif kualitatif dengan metode pendekatan model bisnis kanvas (BMC) yang dilengkapi SWOT dan blue ocean strategy. Responden meliputi pihak internal dan eksternal. Pihak internal, yaitu ketua koperasi, pengawas, manager, KA unit simpan pinjam dan anggota koperasi yang memenuhi kualifikasi sebagai responden. Pihak eksternal yaitu ketua serikat pekerja PT. Chingluh dan Dinas Koperasi dan UMKM Jakarta Timur. Hasil penelitian yang didapatkan yaitu ide pertama terpacu dari beberapa titik pusat inovasi, diantaranya pada titik aktivitas kunci (key activities) dimana KSU Pinto Jaya melakukan pembentukan unit dagang yang tujuannya untuk memenuhi kebutuhan anggota dan meningkatkan pendapatan. Sedangkan ide selanjutnya titik awal pembentukan inovasi dimulai dari penambahan pada key resources untuk mendukung dan meningkatkan key activities. Pembuatan website resmi dan aplikasi komputer dilakukan oleh KSU Pinto Jaya menjadi titik awal pembentukan ide model bisnis yang didasarkan pada kondisi dimana pemanfaatan teknologi informasi oleh KSU Pinto Jaya yang masih kurang optimal.
\end{abstract}

Kata kunci: bisnis model kanvas, blue ocean strategy, analisis SWOT, Pinto Jaya

${ }^{1}$ Corresponding author:

Email: dvd_andreas@yahoo.com 


\section{PENDAHULUAN}

Indonesia merupakan negara yang menganut sistem ekonomi kerakyatan, dimana pengembangan ekonomi kerakyatan sangat identik dengan pengembangan koperasi. Latar belakang sejarah perekonomian nasional menunjukkan bahwa koperasi adalah lembaga yang diciptakan untuk melindungi kaum miskin dan lemah. Koperasi dikembangkan untuk mewujudkan demokrasi ekonomi yaitu pemerataan pendapatan masyarakat melalui pertumbuhan koperasi-koperasi yang sehat. Sejak awal kelahirannya, koperasi diharapkan menjadi soko guru perekonomian Indonesia. Pola pengorganisasian dan pengelolaannya yang melibatkan partisipasi setiap anggota dan pembagian hasil usaha yang cukup adil menjadikan koperasi sebagai harapan pengembangan perekonomian Indonesia. Koperasi merupakan bagian dari tata susunan ekonomi, hal ini berarti bahwa dalam kegiatannya koperasi turut mengambil bagian bagi tercapainya kehidupan ekonomi yang sejahtera, baik bagi orang-orang yang menjadi anggota perkumpulan itu sendiri maupun untuk masyarakat di sekitarnya. Koperasi sebagai perkumpulan untuk kesejahteraan bersama, melakukan usaha dan kegiatan di bidang pemenuhan kebutuhan bersama dari para anggotannya. Menurut UU No 25 Tahun 1992, koperasi Indonesia adalah badan usaha yang beranggotakan orang-orang, seseorang, atau badan hukum koperasi dengan melandaskan kegiatannya berdasarkan prinsip koperasi, sekaligus sebagai gerakan ekonomi rakyat yang berdasarkan asas kekeluargaan. Koperasi secara umum memiliki fungsi dan peranan, yaitu membangun dan mengembangkan potensi dan kemampuan ekonomi anggota pada khususnya dan masyarakat pada umumnya untuk meningkatkan kesejahteraan ekonomi dan sosialnya, juga berperan serta secara aktif dalam upaya mempertinggi kualitas kehidupan manusia dan masyarakat.

Menurut Suryanto dan Nurhadi (2003), terdapat beberapa jenis koperasi, diantaranya, koperasi konsumen, koperasi produsen, koperasi pemasaran, koperasi simpan pinjam, koperasi jasa, dan koperasi serba usaha. Koperasi serba usaha merupakan koperasi yang kegiatan ekonominya lebih dari satu bidang usaha, oleh karena itu dalam koperasi serba usaha, bidang-bidang usaha atau kegiatan ekonomi seperti produksi, konsumsi, kredit, pemasaran, dan jasa dilakukan oleh koperasi itu secara bersama (Suryanto dan Nurhadi, 2003). Saat ini, secara bisnis koperasi masih didominasi usaha simpan pinjam yaitu sebanyak
79.543 unit $(51,97 \%)$ dari total koperasi 153.050 unit (Sumartomjon, 2017).

Koperasi Pinto Jaya merupakan koperasi yang berlokasi di Cipinang Melayu, Jakarta Timur dan berdiri sejak tahun 2011. Koperasi Pinto Jaya memiliki status badan hukum sebagai koperasi serba usaha dan telah mendapat pengesahan oleh Menteri Koperasi dan Usaha Kecil dan Menengah Republik Indonesia (UMKM) dengan Nomor237/BH/XII.5/-1.82931/VIII/2011.Berdasarkan perkembangan jaman KSU Pinto Jaya selama ini hanya menjalankan atau mengoptimalkan pada satu unit saja, yaitu unit usaha simpan pinjam. Perkembangan usaha KSU Pinto Jaya dapat dilihat dari jumlah anggota yang tergabung di koperasi. Pada awal tahun pendirian koperasi, jumlah anggota yang tergabung dalam KSU Pinto Jaya berjumlah 20 anggota dengan penambahan sebanyak 268 anggota menjadi 288 anggota pada akhir tahun awal berdirinya KSU Pinto Jaya.

Sejak awal berdiri pada tahun 2011, KSU Pinto Jaya telah memegang status badan hukum sebagai koperasi serba usaha. Koperasi serba usaha merupakan jenis koperasi yang memiliki lebih dari satu unit bisnis, namun saat ini kegiatan usaha KSU Pinto Jaya hanya terfokus pada unit usaha simpan-pinjam. Kegiatan unit usaha simpan pinjam adalah menghimpun dana dari para anggota koperasi dan menyalurkan dana melalui kegiatan usaha simpan pinjam. KSU Pinto Jaya memiliki potensi untuk dikembangkan sesuai dengan fungsi koperasi serba usaha, dilihat dari perkembangan anggota koperasi yang tertarik untuk bergabung bersama KSU Pinto Jaya dan juga perkembangan aktiva KSU Pinto Jaya. Sebagai benchmark, koperasi yang sudah memiliki prestasi dan kemajuan bisnis seperti Koperasi Sejahtera Bersama (KSB). Pada Oktober 2017, KSB menerima pengukuhan penghargaan sebagai Koperasi Terbaik oleh Kementerian Koperasi dan Usaha Kecil Menengah dengan beberapa kategori dalam acara 100 Koperasi Besar Indonesia. Dipenghujung tahun 2017 KSB kembali dinobatkan menjadi Koperasi Terbaik se-Jawa Barat, lalu sebagai Koperasi Simpan Pinjam Terbaik Ke-2 di Tingkat Nasional, Koperasi Terbaik Ke-7 di Tingkat Nasional, dan yang tidak kalah membanggakan bahwa KSP-SB juga mendapatkan penghargaan atas Koperasi Berbasis IT Terbaik di Tingkat Nasional. Hal tersebut menunjukkan bahwa koperasi tidak hanya merupakan bisnis dengan skala kecil melainkan dapat berkembang dengan skala usaha nasional bahkan menuju internasional. 
Pengembangan koperasi perlu diteruskan, karena pengembangan memerlukan proses, waktu dan ketekunan serta konsistensi dalam pelaksanaan, berkesinambungan untuk mengatasi semua masalah yang ada. Oleh karena itu, perlu dibuat suatu rancangan pengembangan strategi usaha untuk KSU Pinto Jaya agar dapat terus berkembang mengikuti tren bisnis saat ini dan mampu bertahan sebagai wadah kelembagaan bisnis yang berkonstribusi terhadap peningkatan kesejahteraan anggotanya secara berkelanjutan.

Penelitian ini bertujuan untuk merancang ide perencanaan model bisnis KSU Pinto Jaya di masa depan dengan melihat kondisi BMC KSU Pinto Jaya saat ini dan SWOT. Menurut Giesen (2010) bahwa model bisnis harus mampu memperlihatkan peluang yang signifikan, baik disaat pertumbuhan ekonomi yang pesat, maupun saat terjadi penurunan kondisi perekonomian.

\section{METODE PENELITIAN}

Penelitian ini dilakukan pada salah satu koperasi serba usaha yang berlokasi di Pangkalan Jati, Cipinang Melayu, Jakarta Timur, dengan unit cabang KSU yang berlokasi di Pasar Kemis, Tangerang, Banten. Pemilihan lokasi ini dilakukan secara sengaja (purposive). Penelitian dilaksanakan pada bulan Juni 2017 sampai Desember 2017.

Jenis data yang digunakan dalam penelitian ini adalah data primer dan data sekunder. Data primer merupakan sumber informasi utama yang diperlukan untuk menjawab penelitian. Dalam penelitian ini, data primer diperoleh dari kuesioner oleh responden, wawancara mendalam dan secara langsung, serta Focus Group Discussion (FGD). Data tersebut didapat dari pihak internal dan eksternal. Pihak internal meliputi ketua koperasi, pengawas, manager, KA unit simpan pinjam dan anggota koperasi yang memenuhi kualifikasi sebagai responden. Pihak eksternal meliputi ketua serikat pekerja PT. Chingluh dan Dinas Koperasi dan UMKM Jakarta Timur. Data primer yang diperlukan dalam penelitian ini antara lain meliputi keadaan umum bisnis dan kondisi KSU Pinto Jaya. Selain itu juga dengan data yang berhubungan dengan sembilan aspek dalam business model canvas (BMC). Data sekunder merupakan sumber infomasi untuk melengkapi dalam menjawab penelitian. Data sekunder diperoleh dari dokumen perusahaan yang terkait dengan masalah yang diteliti, serta didukung oleh data-data studi literatur, publikasi pemerintah dan swasta, jurnal-jurnal ilmiah serta hasil penelitian yang telah dilakukan sebelumnya yang relevan dengan objek atau masalah yang sedang diteliti.

Penelitian ini menggunakan analisis sembilan elemen BMC yang diadopsi dari Osterwalder dan Pigneur (2012). Penelitian ini juga menggunakan metode FGD sebagai dasar dari penentuan model bisnis KSU Pinto Jaya berdasarkan BMC dan penentuan strategi pengembangan model bisnis masa depan. Metode FGD ini bertujuan untuk memudahkan pemetaan BMC yang sesuai dengan kondisi KSU Pinto Jaya saat ini. Pendekatan ini berpedoman pada kuesioner yang diberikan kepada responden yaitu pengurus dan juga anggota koperasi yang dipilih langsung oleh Ketua Koperasi. Pertanyaan kuesioner atau wawancara tersebut mewakili dari sembilan elemen yang terdapat pada BMC, sehingga mendapatkan gambaran model bisnis organisasi saat ini secara akurat. Selanjutnya dilakukan analisis SWOT pada sembilan elemen bisnis kanvas yang akan menentukan alternatif strategi pengembangan bisnis KSU Pinto Jaya. Secara singkat, kerangka pemikiran penelitian dapat dilihat pada Gambar 1.

\section{HASIL}

\section{Identifikasi Elemen-elemen Model Bisnis KSU Pinto Jaya}

Proses identifikasi elemen-elemen model bisnis ini melibatkan pihak internal dari pengelolaan KSU Pinto Jaya yang terdiri dari ketua koperasi, pengawas, manajer, kepala unitsimpan pinjam berserta anggotanya. Responden tersebut dinilai memiliki kapasitas dalam memberikan informasi yang relevan terkait dengan data yang dibutuhkan untuk mengidentifikasi sembilan elemen BMC sebagai potret kondisi model bisnis KSU saat ini. Adapun hasil identifikasi kesembilan elemen BMC pada KSU Pinto Jaya saat ini adalah sebagai berikut.

Customer segment yang dimiliki oleh KSU Pinto Jaya ditujukan kepada seluruh masyarakat umum, artinya KSU Pinto Jaya dapat menawarkan secara luas kepada masyarakat umum agar dapat menjadi customer. Namun, pemasaran secara massal dianggap kurang efektif sehingga perlu diklasifikasi ke dalam segmen 
tertentu yang memiliki karakteristik yang sama, guna menetapkan prioritas dan mengelola sumber daya koperasi dengan optimal. Rowley (2002), menyatakan bahwa pengetahuan tentang pelanggan adalah aset penting bagi perusahaan. Berdasarkan hasil observasi, pengisian kuesioner dan kesepakatan bersama dalam FGD maka customer segment yang telah dimiliki oleh KSU Pinto Jaya adalah karyawan pabrik PT Chingluh, pelaku usaha kecil dilingkungan sekitar (UMKM), dan anggota koperasi itu sendiri. Hal yang menarik dari koperasi adalah anggota koperasi selain sebagai pemilik dari koperasi juga merupakan customer bagi koperasi. Anggota KSU Pinto Jaya saat ini didominasi oleh karyawan pabrik PT Chingluh yang bergabung dengan serikat pekerja. Saat ini, karyawan PT Chingluh tidak seluruhnya menjadi anggota KSU Pinto Jaya karena banyak juga karyawan pabrik yang tidak bergabung ke dalam serikat pekerja. Selain karyawan pabrik, KSU Pinto Jaya mempunyai anggota yang berasal dari pelaku UMKM dilokasi sekitar. Jumlah anggota berdasarkan segmen pelanggan KSU Pinto Jaya dapat dilihat pada Tabel 2.
Value proposition adalah tentang nilai apa yang akan diberikan oleh pelaku bisnis kepada segmen pasar yang dilayani. Nilai yang ditawarkan oleh KSU Pinto Jaya untuk pelanggannya yaitu dengan menawarkan penyesuaian (kustomisasi). Penyesuaian (kustomisasi) ini dibentuk dengan menyesuaikan produk atau jasa untuk memenuhi kebutuhan spesifik pelanggan individu atau segmen pelanggan yang juga menciptakan nilai. Bainnaura (2014) berpendapat bahwa perusahaan harus memiliki pengetahuan mengenai apa yang diinginkan oleh pelanggan dan mengetahui bagaimana memenuhi kebutuhan tersebut untuk memperoleh keuntungan atas apa yang ditawarkan. Berdasarkan hasil wawancara dengan pihak internal, hasil observasi, pengisian kuesioner dan kesepakatan bersama dalam FGD elemen proporsisi nilai perusahaan terdiri dari sistem pembayaran dan tenor waktu yang dapat disesuaikan, lokasi kantor pelayanan yang berada dekat dengan pabrik PT Chingluh, kecepatan, kenyamanan, dan kepastian pelayanan, serta biaya dan bunga yang rendah.

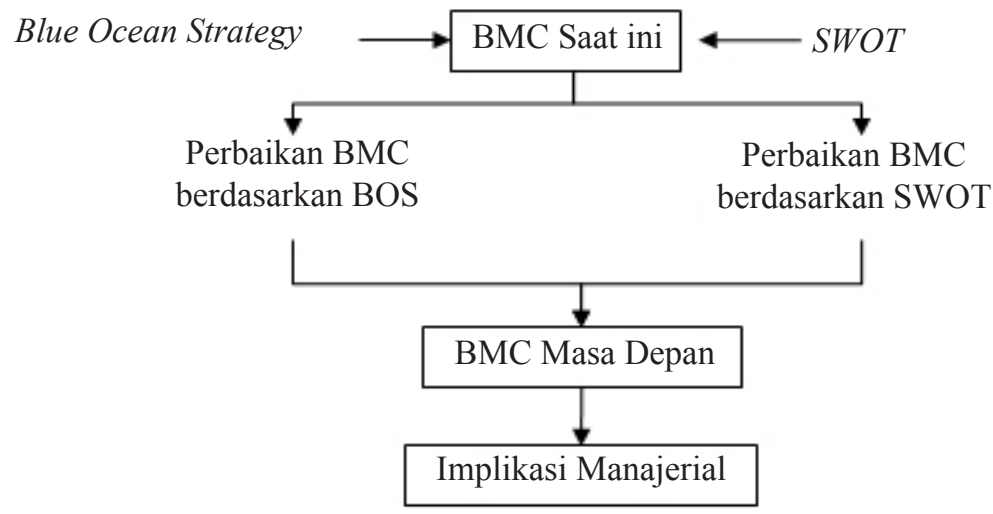

Gambar 1. Kerangka pemikiran penelitian

Tabel 2. Jumlah anggota berdasarkan segmen pelanggan KSU Pinto Jaya

\begin{tabular}{ccc}
\hline Tahun & Karyawan Pabrik PT Chingluh (orang) & UMKM (orang) \\
\hline 2011 & 286 & 2 \\
2012 & 493 & 9 \\
2013 & 656 & 9 \\
2014 & 910 & 14 \\
2015 & 1217 & 29 \\
2016 & 1524 & 29 \\
\hline
\end{tabular}


Channels dapat diartikan sebagai kegiatan pemasaran yang berusaha memperlancar dan mempermudah pencapaian barang dan jasa dari produsen ke konsumen, sehingga penggunaannya sesuai dengan yang diperlukan (Tjiptono, 2008). Penyampaian value proposition yang saat ini diterapkan oleh KSU Pinto Jaya adalah melalui indirect dan direct channel. KSU Pinto Jaya menggunakan saluran pelanggan secara langsung (direct), yang artinya menggunakan tempat sendiri (kantor koperasi) untuk menyampaikan value proposition-nya. Oleh sebab itu, pemilihan lokasi merupakan faktor yang penting. KSU Pinto Jaya harus mempertimbangkan akses jalan, kemudahan pelanggan untuk mengetahui posisi kantor, dan kestrategisan lokasi. Selain itu, saluran tidak langsung (indirect) yang dilakukan pengelola dalam mencapai customer adalah melalui mitra dimana pengelola berkoordinasi dan kerjasama dengan beberapa pihak dalam hal pengelolaan, pengembangan, serta promosi seperti anggota koperasi dan serikat pekerja PT Chingluh, melalui brosur, dan word of mouth. Salah satu saluran pelanggan yang efektif adalah interaksi manusia dalam berkomunikasi mulut ke mulut, yang dimaksud adalah pelanggan akan memberikan komentar terhadap produk yang telah dibelinya dan kemudian akan menyebar ke konsumen lainnya (Indra, 2017). Menurut Tahernejad (2012), pemahaman informasi dari mulut ke mulut adalah saran yang disampaikan secara informal yang berlangsung sesama pelanggan. Informasi tersebut dianggap sebagai efek yang sangat kuat pada perilaku pelanggan yang menunjukkan respon pelanggan terhadap sesuatu yang ia dapatkan.

Customer relationship merupakan salah satu faktor penting dalam berlangsungnya suatu bisnis. Penerapan hubungan pelanggan yang dilakukkan KSU Pinto Jaya menggunakan personal assistance secara langsung dan tidak langsung. Bantuan personal yang dilakukan secara langsung, yaitu pemberian informasi mengenai koperasi secara tatap muka dan juga pelaksanaan kegiatan simpan pinjam. Sedangkan, bantuan personal secara tidak langsung dapat dilakukan melalui media komunikasi seperti telepon, sms, dan instant messenger. Hal ini dilakukan dengan tujuan mempertahankan anggota serta menjaga hubungan antara anggota dan pengurus tetap terjalin. Menurut Berman (2012), keputusan customer dalam memilih suatu produk semakin banyak diperngaruhi oleh informasi yang diperoleh dari instant messenger. Penerapan hubungan pelanggan selanjutnya adalah melalui keanggotaan, dimana KSU Pinto Jaya melalui keangggotaannya memungkinkan pelanggan untuk bertukar pengetahuan, memecahkan masalah, dan berperan serta dalam kegiatan koperasi. Selain itu juga, KSU Pinto Jaya menerapkan adanya RAT (Rapat Anggota Tahunan) untuk mengetahui pelaksanaan kegiatan yang ada di koperasi, dan pembagian SHU (Sisa Hasil Usaha). Penerapan hubungan pelanggan lainnya, yaitu penyediaan kotak kritik dan saran yang digunakan sebagai wadah atau sarana penyampaian ulasan kinerja koperasi.

Revenue stream merupakan komponen yang dianggap paling vital. Umumnya perusahaan memperoleh pendapatannya dari pelanggan. Sehingga, revenue stream menggambarkan sumber pendapatan yang dihasilkan perusahaan dalam memberikan value proposition kepada customer segments. Berdasarkan hasil observasi, pengisian kuesioner dan kesepakatan bersama dalam FGD, maka diketahui revenue stream yang dimiliki KSU Pinto Jaya adalah keuntungan kredit (bunga), dan biaya administrasi pinjaman. Arus pendapatan yang dihasilkan dari keuntungan kredit (bunga) adalah imbal jasa atas proses peminjaman uang dalam suatu periode tertentu. Dalam hal ini, koperasi memperoleh pendapatan bunga dari pinjaman-pinjaman yang dilakukan anggota ataupun non anggota. Selain itu, arus pendapatan kedua yaitu biaya administrasi pinjaman yang diperoleh pada saat pencairan pinjaman.

Key resources merupakan sumber daya utama yang dibutuhkan perusahaan dalam membuat dan menawarkan value proposition, meraih pasar, menjaga hubungan dengan customer segments dan memperoleh pendapatan (Priyono, 2015). Sumber daya utama yang dimiliki oleh KSU Pinto Jaya dalam menjalankan bisnis berupa sumber daya fisik dan fasilitas, sumber daya intelektual, sumber daya manusia dan sumber daya finansial. Sumber daya fisik yang dimiliki oleh KSU Pinto Jaya berupa bangunan kantor beserta fasilitas kantor sebagai penunjang aktivitas operasional koperasi. KSU Pinto Jaya memiliki dua kantor yaitu kantor pusat yang terletak di Cipinang Melayu, Jakarta Timur dan kantor cabang yang terletak di Kawasan Industri Pasar Kemis, Cikupa, Tangerang, Banten. Fasilitas kantor utama yang dimiliki oleh KSU Pinto Jaya antara lain; komputer, printer, telepon, meja kerja, aplikasi sederhana sebagai penunjang database, dan ruang pelayanan. Sumber daya intelektual yang dimiliki oleh KSU Pinto Jaya yaitu database. Sumber daya manusia yang dimiliki adalah pengurus, pengelola dan anggota koperasi. Pengurus dan anggota merupakan sumber daya yang sangat penting dalam menjalankan seluruh kegiatan yang dilakukan koperasi. Sumber daya finansial yang dimiliki oleh KSU Pinto Jaya berasal dari 
dana yang dikumpulkan dari anggota dan dari luar, yaitu dari koperasi lain, bank atau lembaga keuangan lainnya.

Key activities yang sangat menentukan proses kegiatan KSU Pinto Jaya yaitu dengan melakukan pengumpulan anggota, pelayanan anggota, manajemen data, funding, lending dan collection. Kegiatan funding yang dilakukan adalah kegiatan menghimpun dana dari anggota atau calon anggota yang berbentuk simpanan atau penyertaan modal guna penguatan modal kedalam. Pengumpulan dana sangat diperlukan sebagai modal koperasi. Pengumpulan dana diperoleh melalui simpanan pokok, simpanan wajib, dan modal penyertaan yang berasal dari anggota koperasi itu sendiri. Lending adalah pembiayaan yang diberikan kepada anggota atau calon anggota baik untuk keperluan produktif maupun konsumtif yang berasal dari hasil funding. Koperasi melakukan pemberian pinjaman kepada setiap anggota maupun non anggota yang melakukan pengajuan pinjaman. Kegiatan collecting yang dilakukan merupakan pemungutan kredit dari setiap peminjaman yang dilakukan oleh anggota koperasi. Penagihan dilakukan setiap bulannya.

Key partnership yang dimiliki KSU Pinto Jaya, yaitu anggota koperasi, lembaga keuangan, Serikat Pekerja PT Chingluh, dan konsultan keuangan. Menurut Tuten dan Urban (2001), keberadaan partner dalam sebuah bisnis sangat penting karena dapat mempermudah dan mempercepat proses bisnis yang ada. Anggota koperasi merupakan salah satu mitra dari KSU Pinto Jaya, suatu koperasi dapat berjalan dengan baik tidak terlepas dari peran serta dan keaktifan anggota koperasi tersebut. Mitra dari KSU Pinto Jaya lainnya yaitu lembaga keuangan. Kerjasama yang dilakukan dengan lembaga keuangan adalah penambahan modal dari investasi lembaga keuangan tersebut kepada koperasi. Selain itu juga, KSU Pinto Jaya membutuhkan hadirnya lembaga keuangan sebagai tempat penyimpanan dana dan membantu penagihan kredit dari pinjaman anggota melalui sistem auto-debet. Saat ini, serikat pekerja PT. Chingluh merupakan partner yang berperan besar dalam KSU Pinto Jaya, serikat pekerja ini yang menjadi penyalur dan pemberi informasi kepada karyawan di PT. Chingluh yang tergabung dalam serikat pekerja untuk bergabung menjadi anggota KSU Pinto Jaya. Serikat pekerja ini juga bertugas untuk menjadi salah satu pengawas bagi anggota maupun koperasi itu sendiri. Mitra kunci lainnya adalah jasa akuntansi yang membantu KSU Pinto Jaya untuk membuat laporan keuangan dan perpajakan. Jasa akuntansi yang bekerjasama dengan KSU Pinto Jaya adalah PT Global Sakti Prima.

Cost structure yang terdapat di KSU Pinto Jaya terdiri dari fixed cost dan variable cost. Untuk pengeluaran KSU Pinto Jaya yang termasuk fixed cost adalah biaya tenaga kerja. biaya jasa akuntansi dan biaya sewa bangunan. Sedangkan yang menjadi variabel cost antara lain biaya pelatihan, biaya modal, biaya promosi, biaya operasional dan pembayaran pajak. Biaya operasional pada KSU Pinto Jaya meliputi biaya penagihan, biaya transportasi, dan biaya cetak dokumen atau berkas. Model bisnis kanvas KSU Pinto Jaya saat ini dapat dilihat pada Gambar 2.

\section{Analisis SWOT BMC Model Bisnis KSU Pinto Jaya}

Tahapan selanjutnya setelah dilakukan identifikasi kondisi setiap elemen model bisnis kanvas saat ini adalah melakukan pemetaan terhadap kekuatan, kelemahan, ancaman dan peluang dari setiap elemen BMC KSU Pinto Jaya. Lozano dan Valles (2007) menjelaskan bahwa analisis SWOT secara luas diakui dan itu merupakan suatu dasar yang penting untuk belajar tentang situasi dan untuk merancang prosedur mendatang yang dapat dilihat diperlukan untuk berpikir dalam cara strategis. Analisis SWOT dapat menjadi alat yang berguna untuk perencanaan strategis proses pengelolaan lingkungan (Nikolao dan Evangelinos, 2010). Hasil dari identifikasi SWOT tiap elemen BMC digunakan untuk perancangan model bisnis baru yang akan dijalankan KSU Pinto jaya di masa depan. Berdasarkan hasil wawancara, pengisian kuesioner dan observasi maka hasil identifikasi SWOT kesembilan elemen BMC KSU Pinto Jaya dapat dilihat pada Tabel 3.

Dalam mendesain model bisnis baik menyempurnakan maupun membuat prototipe model bisnis lain, membangun ide merupakan bagian yang paling mendasar dan terpenting yang harus dilakukan perusahaan. Inovasi model bisnis yang transformatif mempengaruhi lebih dari satu building block. Terdapat empat pusat inovasi model bisnis, yaitu terpacu oleh sumber daya, terpacu oleh penawaran, terpacu oleh pelanggan, dan terpacu oleh keuangan (Osterwalder dan Pigneur, 2010). Masingmasing pusat inovasi ini posisinya sebagai titik awal bagi perubahan besar model bisnis dan memberikan dampak yang kuat bagi kedelapan building block lainnya. 


\begin{tabular}{|c|c|c|c|c|c|}
\hline \multirow[t]{2}{*}{$\begin{array}{l}\text { Key Partners } \\
\text { - Anggota koperasi } \\
\text { - Lembaga } \\
\text { keuangan } \\
\text { - Serikat pekerja PT } \\
\text { Chingluh } \\
\text { - Jasa akuntansi }\end{array}$} & $\begin{array}{l}\text { Key Activities } \\
\text { - Pengumpulan \& } \\
\text { pelayanan anggota } \\
\text { - Manajemen data } \\
\text { - Funding, Lending, } \\
\quad \text { Collection }\end{array}$ & \multirow{2}{*}{\multicolumn{2}{|c|}{$\begin{array}{l}\text { Value Propositions } \\
\text { - Sistem } \\
\text { pembayaran dan } \\
\text { tenor waktu yang } \\
\text { dapat disesuaikan } \\
\text { - Lokasi dekat } \\
\text { dengan pabrik PT } \\
\text { Chingluh } \\
\text { - Biaya dan bunga } \\
\text { yang rendah } \\
\text { - Kecepatan, } \\
\text { kenyamanan, } \\
\text { dan kepastian } \\
\text { pelayanan }\end{array}$}} & $\begin{array}{l}\text { Customer } \\
\text { Relationships } \\
\text { - Personal } \\
\text { assistance } \\
\text { - Komunikasi (SMS, } \\
\text { Telepon, instant } \\
\text { messenger) } \\
\text { - Keanggotaan }\end{array}$ & \multirow[t]{2}{*}{$\begin{array}{l}\text { Customer Segments } \\
\text { - Karyawan pabrik } \\
\text { PT Chingluh } \\
\text { - Pelaku usaha kecil } \\
\text { dilingkungan } \\
\text { sekitar (UMKM) } \\
\text { - Anggota }\end{array}$} \\
\hline & $\begin{array}{l}\text { Key Resources } \\
\text { - Pengurus } \\
\text { - Anggota } \\
\text { - Kantor } \\
\text { - Sumberdaya } \\
\text { finansial } \\
\text { - Database anggota }\end{array}$ & & & $\begin{array}{l}\text { Channels } \\
\text { - Kantor } \\
\text { - Serikat pekerja PT } \\
\text { Chingluh } \\
\text { - Brosur } \\
\text { - Word of mouth } \\
\text { - Kotak kritik dan } \\
\text { saran }\end{array}$ & \\
\hline \multicolumn{3}{|l|}{$\begin{array}{l}\text { Cost Structure } \\
\text { Fixed cost : } \\
\text { - Biaya tenaga kerja } \\
\text { - Biaya jasa akuntansi } \\
\text { - Biaya sewa bangunan }\end{array}$} & \multicolumn{3}{|c|}{$\begin{array}{l}\text { Revenue Streams } \\
\text { - Keuntungan dari kredit / bunga } \\
\text { - Biaya administrasi pinjaman }\end{array}$} \\
\hline
\end{tabular}

Gambar 2. Model bisnis kanvas KSU Pinto Jaya saat ini

Tabel 3. Hasil analisis SWOT kesembilan elemen BMC KSU Pinto Jaya

\begin{tabular}{|c|c|c|c|c|}
\hline Aspek & Kekuatan & Kelemahan & Peluang & Ancaman \\
\hline $\begin{array}{l}\text { Customer } \\
\text { Segment }\end{array}$ & $\begin{array}{l}\text { Anggota koperasi } \\
\text { adalah customer, tingkat } \\
\text { berpindah pelanggan } \\
\text { rendah }\end{array}$ & $\begin{array}{l}\text { Koperasi memiliki } \\
\text { cakupan pelanggan } \\
\text { hanya pada satu unit } \\
\text { usaha }\end{array}$ & $\begin{array}{l}\text { Pertumbuhan } \\
\text { penduduk dan } \\
\text { kebutuhan semakin } \\
\text { meningkat }\end{array}$ & $\begin{array}{l}\text { Lembaga keuangan } \\
\text { lainnya }\end{array}$ \\
\hline $\begin{array}{l}\text { Value } \\
\text { Proporsition }\end{array}$ & $\begin{array}{l}\text { Memiliki sinergi yang } \\
\text { kuat antara produk dan } \\
\text { layanan }\end{array}$ & $\begin{array}{l}\text { Koperasi belum dapat } \\
\text { memenuhi kebutuhan } \\
\text { anggotanya }\end{array}$ & $\begin{array}{l}\text { Membuka unit bisnis } \\
\text { baru }\end{array}$ & $\begin{array}{l}\text { Persaingan dengan } \\
\text { lembaga keuangan sejenis }\end{array}$ \\
\hline Channels & $\begin{array}{l}\text { Ketersediaan kantor, } \\
\text { bekerjasama dengan } \\
\text { serikat pekerja PT } \\
\text { Chinglu }\end{array}$ & Promosi belum maksimal & $\begin{array}{l}\text { Kemajuan teknologi, } \\
\text { kerjasama dengan } \\
\text { mitra lain }\end{array}$ & $\begin{array}{l}\text { Pengambil alihan saluran } \\
\text { oleh pesaing }\end{array}$ \\
\hline $\begin{array}{l}\text { Customer } \\
\text { Relationship }\end{array}$ & $\begin{array}{l}\text { Diadakan Rapat Anggota } \\
\text { Tahunan secara rutin, } \\
\text { hubungan pelanggan kuat }\end{array}$ & $\begin{array}{l}\text { Merek perusahaan } \\
\text { lemah, biaya berpindah } \\
\text { pelanggan rendah }\end{array}$ & $\begin{array}{l}\text { Penggunaan sistem } \\
\text { online }\end{array}$ & \\
\hline $\begin{array}{l}\text { Revenue } \\
\text { Stream }\end{array}$ & $\begin{array}{l}\text { Pendapatan dapat } \\
\text { diprediksi, arus } \\
\text { pendapatan berkelanjutan }\end{array}$ & $\begin{array}{l}\text { Mengeluarkan biaya } \\
\text { tinggi sebelum } \\
\text { mengumpulkan } \\
\text { pendapatan }\end{array}$ & $\begin{array}{l}\text { Membuka unit usaha } \\
\text { baru }\end{array}$ & $\begin{array}{l}\text { Badan usaha non- } \\
\text { koperasi, pengembalian } \\
\text { pinjaman (gagal / telat) }\end{array}$ \\
\hline $\begin{array}{l}\text { Key } \\
\text { Resources }\end{array}$ & $\begin{array}{l}\text { Koperasi dapat } \\
\text { memprediksi kebutuhan } \\
\text { sumber daya utama }\end{array}$ & $\begin{array}{l}\text { Jumlah tenaga kerja } \\
\text { terbatas }\end{array}$ & $\begin{array}{l}\text { Membuka unit usaha } \\
\text { baru, pembukaan gerai }\end{array}$ & $\begin{array}{l}\text { Investor beralih ke } \\
\text { lembaga keuangan lain }\end{array}$ \\
\hline $\begin{array}{l}\text { Key } \\
\text { Activities }\end{array}$ & $\begin{array}{l}\text { Pendataan rutin } \\
\text { menggunakan teknologi } \\
\text { berupa laporan keuangan }\end{array}$ & $\begin{array}{l}\text { Aktivitas kunci mudah } \\
\text { ditiru }\end{array}$ & $\begin{array}{l}\text { Penggunaan teknologi } \\
\text { terbaru }\end{array}$ & $\begin{array}{l}\text { Persaingan dengan } \\
\text { lembaga keuangan sejenis }\end{array}$ \\
\hline $\begin{array}{l}\text { Key } \\
\text { Partnerships }\end{array}$ & $\begin{array}{l}\text { Memiliki serikat kerja PT } \\
\text { Chinglu }\end{array}$ & $\begin{array}{l}\text { Sangat bergantung pada } \\
\text { mitra, kurangnya mitra } \\
\text { lainnya }\end{array}$ & $\begin{array}{l}\text { Koperasi lainnya, } \\
\text { serikat kerja } \\
\text { perusahaan lain }\end{array}$ & $\begin{array}{l}\text { adanya kolaborasi } \\
\text { mitra dengan pesaing } \\
\text { (kompetitor) }\end{array}$ \\
\hline $\begin{array}{l}\text { Cost } \\
\text { Structure }\end{array}$ & $\begin{array}{l}\text { Total biaya lebih kecil } \\
\text { dari total keuntungan }\end{array}$ & $\begin{array}{l}\text { Penggunaan jasa } \\
\text { konsultan }\end{array}$ & & Biaya yang fluktuatif \\
\hline
\end{tabular}


Pada penelitian ini, penulis menawarkan dua ide perancangan model bisnis berbasis blue ocean strategy. Ide pertama dari perencanaan model bisnis berbasis blue ocean strategy ini terpacu dari beberapa titik pusat inovasi, diantaranya pada titik titik penawaran (value proposition) dan aktivitas kunci (key activities). Pembentukan unit usaha baru, yaitu unit usaha dagang menjadi awal perencanaan ide dari model bisnis ini dimana fungsinya adalah membantu anggota koperasi dalammempromosikan,menyalurkanhasilproduksinya, meningkatkan pendapatan koperasi dan salah satu cara KSU Pinto Jaya dalam melaksanakan pemenuhan kebutuhan anggotanya. Berdasarkan kondisi saat ini dapat diketahui bahwa KSU Pinto Jaya hanya memiliki satu unit usaha yaitu simpan pinjam, sehingga peran dari unit usaha dagang ini mampu memberikan layanan baru bagi anggota. Dalam perencanaan pembentukan unit usaha dagang ini menerapkan sistem pembayaran tunai dan berjangka. Fasilitas pembayaran berjangka hanya berlaku bagi anggota KSU Pinto Jaya, hal ini dilakukan guna mengundang ketertarikan masyarakat untuk bergabung menjadi anggota KSU Pinto Jaya. Dalam menjalankan perencanaan model bisnis ini, KSU Pinto Jaya menjalin kemitraan dengan berbagai distributor untuk mendapatkan harga barang yang lebih murah. Selain itu, KSU Pinto Jaya menjalin mitra dengan serikat pekerja lainnya untuk memperluas segmen pelanggan di perusahaan atau pabrik lainnya. KSU Pinto Jaya juga menjalin hubungan kemitraan dengan koperasi lainnya untuk kerjasama yang dijalankan seperti pertukaran barang dagang hasil produksi anggota dan membantu dalam hal pemenuhan kebutuhan anggota yang dapat saling menguntungkan. Untuk menjalankan unit usaha dagang tersebut, KSU Pinto Jaya membutuhkan penambahan jumlah pengelola agar dapat menjalankan aktivitas unit dagang dengan baik. Pembukaan unit usaha dagang sebagai unit usaha baru KSU Pinto Jaya merupakan titik pusat inovasi yang terpacu oleh aktivitas kunci (key activity), sedangkan sistem pembayaran yang ditawarkan pada perencanaan model bisnis ini merupakan titik pusat inovasi yang terpacu oleh penawaran (value proposition). Kedua titik inovasi ini akan memengaruhi elemen-elemen blok bangunan lainnya.

Pada ide selanjutnya, titik awal pembentukan inovasi dimulai dari perubahan pada key resources untuk meringankan dan mempermudah kegiatan-kegiatan yang dilakukan KSU Pinto Jaya untuk meningkatkan pelayanan bagi pelanggan serta dapat menekan biaya dalam kegiatan operasional KSU Pinto jaya. Pembuatan website resmi dan peningkatan penggunaan teknologi aplikasi komputer pada blok key activities KSU Pinto Jaya menjadi titik awal pembentukan ide model bisnis yang ditawarkan sebagai langkah awal dalam meningkatkan dan memudahkan kegiatan-kegiatan yang dijalankan oleh KSU Pinto Jaya.

Pada perancangan prototype model bisnis yang dikombinasikan dengan prinsip blue ocean strategy mengangkat empat pertanyaan utama, yaitu apa yang bisa diciptakan (create), dihilangkan (eliminate), ditingkatkan (rise), dan dikurangi (reduce) yang mengacu pada kondisi saat ini dan di masa mendatang. Pemberian nomor yang didukung oleh tanda panah pada gambar menunjukan urutan ide, bagaimana perubahan ataupun penambahan pada satu blok bangunan mempengaruhi blok bangunan yang lain dan peneliti menggunakan perbedaan warna untuk memperjelas pemaparan. Gambar 3 menyajikan bisnis model kanvas pada ide perancanaan model bisnis dan Gambar 4 menyajikan ide kerangka empat tindakan prototipe model bisnis.

Secara garis besar implikasi manajerial yang ditawarkan pada penelitian ini kepada pihak KSU Pinto Jaya yaitu, (1) pihak pengurus melakukan penyamaan presepsi serta menetapkan standar atau kriteria individu yang tepat untuk direkrut menjadi pengelola gerai, (2) KSU Pinto Jaya melakukan revisi kebijakan terkait penambahan unit usaha, yaitu unit dagang dan penggunaan website dan aplikasi komputer seperti penambahan pengelola, mitra, dan standar operasional koperasi dalam menjalankan aktivitasnya untuk meningkatkan pelayanan dan menunjang kegiatan usaha koperasi, dan (3) KSU Pinto Jaya melakukan pemilihan terhadap mitra perusahaan layanan pembuatan konten website dan aplikasi komputer dengan mempertimbangkan track record yang dicapai perusahaan tersebut dengan penggalian informasi lebih lanjut mengenai kualitas websitenya dan portofolionya. Penyediaan layanan purna jual yang ditawarkan perusahaan pembuatan website juga dipertimbangkan dalam pemilihan perusahaan pembuatan website tersebut. 


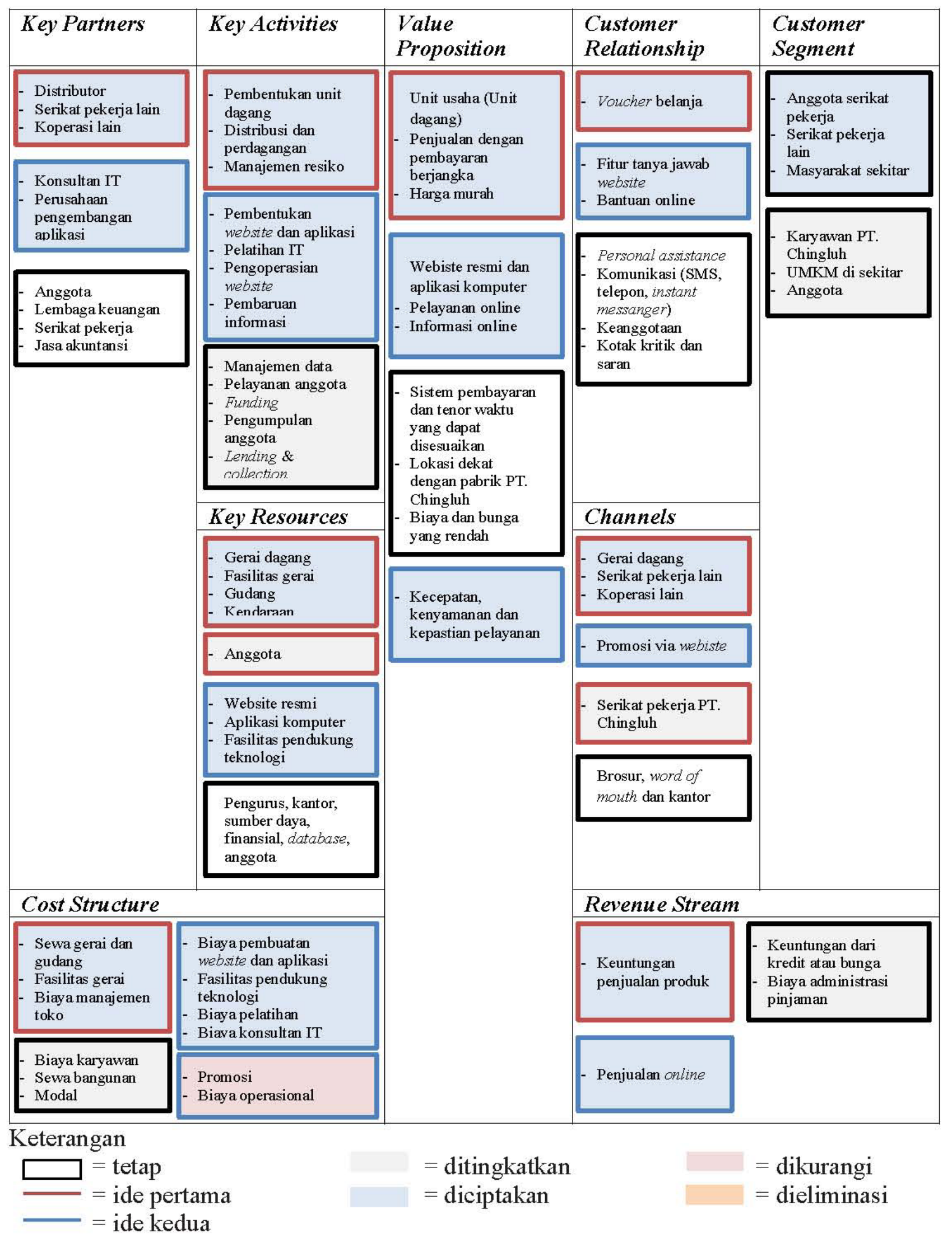

Gambar 3. Bisnis model kanvas pada ide perencanaan model bisnis 


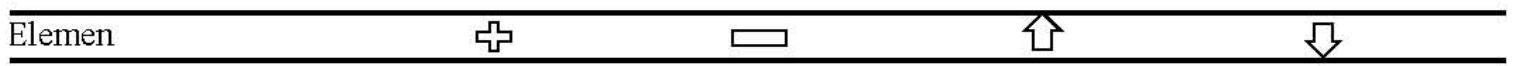

Siapa perusahaan dan apa yang perusahaan miliki? (Key Resources)

Apa yang perusahaan lakukan? (Key Activities)

Siapa yang perusahaan bantu? (Customer Segment)

Bagaimana cara perusahaan membantu? (Value Proposition)

Bagaimana pelanggan mengenali perusahaan? (Channels)

Bagaimana perusahaan berinteraksi? (Customer Relationship)

Siapa yang membantu perusahaan? (Key Partnership)

Apa yang perusahaan dapatkan? (Revenue Stream)

Apa yang perusahaan berikan? (Cost Structure)

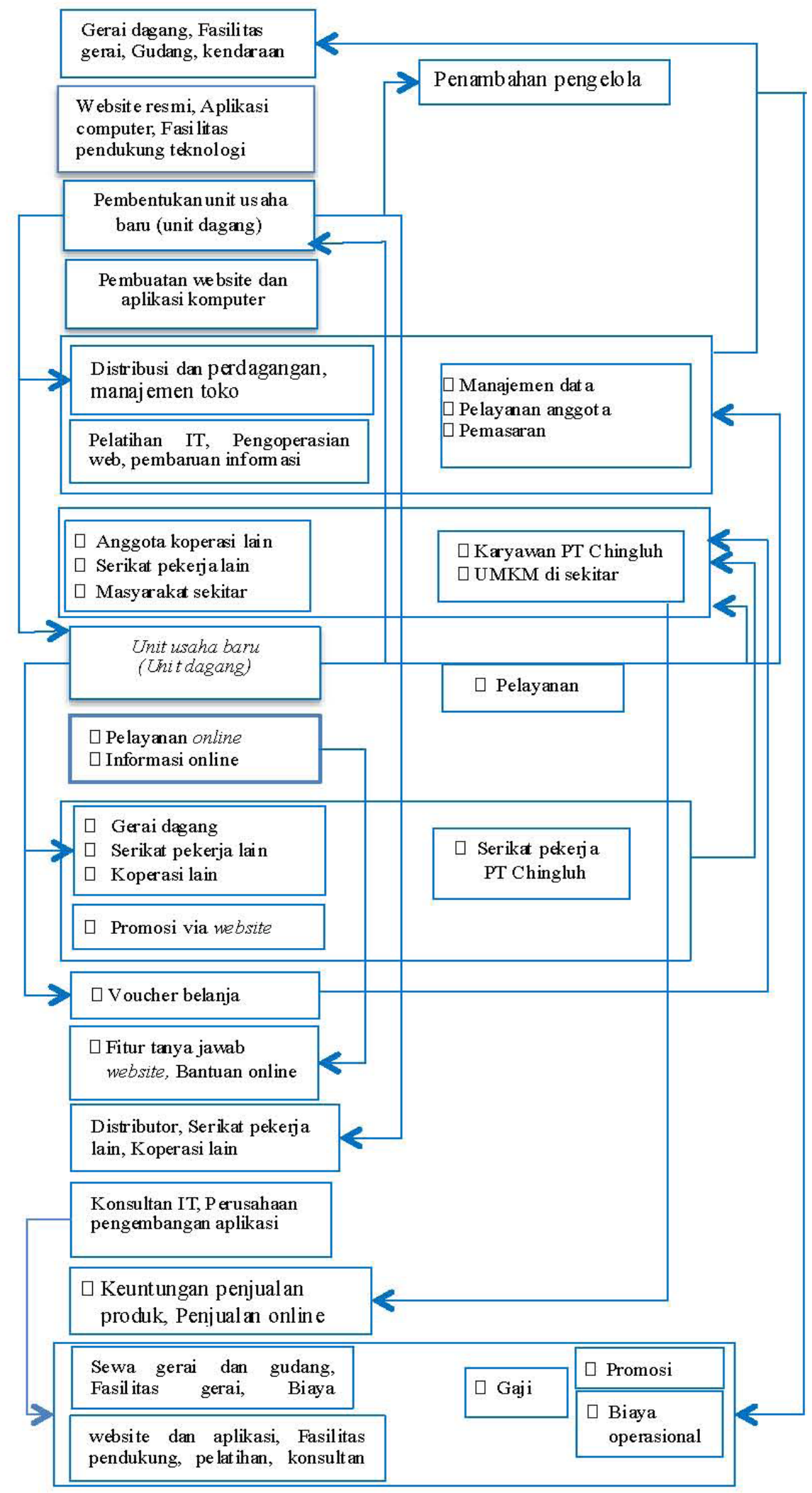

Gambar 4. Ide kerangka empat tindakan prototipe model bisnis 


\section{Implikasi Manajerial}

Penelitian "Analisis Pengembangan Model Bisnis Koperasi Serba Usaha Pinto Jaya" dilakukan untuk menyusun model bisnis yang menghasilkan strategi pengembangan di masa yang akan datang. Model bisnis menurut Mansfield dan Fourie (2003) adalah salah satu acuan yang digunakan untuk memaksimalkan proses penciptaan nilai dalam suatu perusahaan. Tahapan dalam pengembangan bisnis di masa yang akan datang adalah dilakukan berdasarkan evaluasi dari model bisnis saat ini. Evaluasi tersebut berdasarkan pada analisis SWOT terhadap masing-masing pada Sembilan elemen building blocks. Hasil menunjukkan bahwa peningkatan pengunaan teknologi perlu dilakukan agar unit bisnis yang dijalankan oleh KSU Pinto Jaya dapat lebih efektif dan efisien. Implikasi dari hasil analisis SWOT merupakan dasar program yang perlu dikembangkan oleh KSU Pinto Jaya dalam jangka pendek. Adapun program jangka pendek yang perlu diterapkan oleh KSU Pinto Jaya adalah sebagai berikut: Perekrutan tenaga ahli di bidang teknologi informasi (TI), Pengembangan website dan sistem informasi manajemen, maintenance terhadap manajemen sistem informasi.

Tantangan bisnis yang semakin berkembang menuntut manajemen tidak hanya membuat keputusan hanya dengan mendasarkan pada aturan-aturan yang sudah ada, kebijakan-kebijakan lama, dan perhitungan-perhitungan sederhana untuk trend sekarang. Manajemen dituntut untuk melihat trend bisnis masa yang akan datang. Globalisasi informasi telah melanda keseluruh dunia, salah satu hal yang menonjol dalam era ini adalah cepatnya informasi yang dapat diterima sehingga tidak ada lagi perbedaan antara ruang dan waktu (Evi dan Malabay, 2009). Berdasarkan pendekatan model bisnis kanvas yang dilengkapi blue ocean strategy, hasil penelitian ini menawarkan dua ide pengembangan model bisnis berbasis blue ocean strategy yang dapat digunakan KSU Pinto Jaya diantaranya pengembangan unit bisnis yang saat ini sudah ada di unit simpan pinjam yaitu produk kredit/pinjaman namun dikembangkan pinjaman berupa pembiayaan pembeliaan barang elektronik dan kendaraan motor. Kemudian yang kedua adalah pengembangan unit bisnis penjualan barang konsumsi dengan alternatif investasi pada waralaba yang saat ini sudah ada. Program dalam pengembangan bisnis pada unit bisnis simpan pinjam adalah sebagai berikut: Mencari partner usaha yang tepat; proses pemasaran produk kredit pembelian barang elektronik dan kendaraan motor; pengelolaan data; manajem en risiko. Kemudian untuk pengembangan ide bisnis investasi waralaba adalah sebagai berikut: Analisis kelayakan investasi pada waralaba yang saat ini ada; Proses investasi waralaba; Pengelolaan keuntungan dari unit bisnis waralaba

\section{KESIMPULAN DAN SARAN}

\section{Kesimpulan}

Hasil penelitian menawarkan dua ide perencanaan model bisnis berbasis blue ocean strategy yang dapat dijalankan oleh KSU Pinto Jaya dalam mengembangkan bisnis di masa depan. Dua ide perancangan model bisnis berbasis blue ocean strategy dimana kedua ide ini terkait dan dapat mempengaruhi satu sama lain. Ide pertama terpacu dari beberapa titik pusat inovasi, diantaranya pada titik aktivitas kunci (key activities) Lamarque (2005), menyatakan bahwa organisasi dapat terus berjalan dengan baik apabila memiliki aktivitas kunci yang berbeda dengan kompetitor atau aktivitas kuncinya sama dengan kompetitor namun dengan cara yang berbeda. KSU Pinto Jaya melakukan pembentukan unit dagang yang tujuannya untuk memenuhi kebutuhan anggota dan meningkatkan pendapatan. Sedangkan ide selanjutnya titik awal pembentukan inovasi dimulai dari penambahan pada key resources untuk mendukung dan meningkatkan key activities yang dilakukan oleh KSU Pinto Jaya. Pembuatan website resmi dan aplikasi komputer dilakukan oleh KSU Pinto Jaya menjadi titik awal pembentukan ide model bisnis yang didasarkan pada kondisi dimana pemanfaatan teknologi informasi oleh KSU Pinto Jaya yang masih kurang optimal.

\section{Saran}

Saran yang dapat diberikan berdasarkan penelitian yang telah dilakukan adalah penelitian mengenai analisis lingkungan model bisnis yang didalamnya terdapat tren kunci, kekuatan pasar, persaingan industri, dan ekonomi makro, serta tahapan lebih lanjut mengenai persepsi pelanggan atau anggota koperasi di KSU Pinto Jaya. Hal ini dimaksudkan untuk melihat persaingan lingkungan bisnis yang ada disekitar lokasi KSU Pinto Jaya sehingga mendapatkan strategi persaingan lebih lanjut yang dapat diimplementasikan kepada pihak internal. Selain itu, saran lainnya yang dapat 
dilakukan adalah mengetahui keinginan dan kebutuhan pelanggan atau anggota dari KSU Pinto Jaya yang dapat dirangkum dalam analisis persepsi pelanggan. Selain itu secara berkala KSU Pinto Jaya disarankan melakukan perencanaan pengembangan dengan pendekatan model bisnis kanvas untuk melakukan evaluasi serta menemukan peluang. Bagi penelitian selanjutnya, diharapkan melakukan analisa dan evaluasi terkait penerapat sistem berbasis teknologi yang diterapkan dalam bisnis koperasi.

\section{DAFTAR PUSTAKA}

Bagindo M. 2015. Analisis model bisnis ekowisata di Taman Nasional Laut Bunaken dengan pendekatan business model canvas [tesis]. Bogor: Sekolah Pascasarjana, Institut Pertanian Bogor.

Bainnaura A. 2014. Strategi pengembangan hutan pendidikan Gunung Walat (HPGW) menggunakan pendekatan business model canvas [tesis]. Bogor: Sekolah Pascasarjana, Institut Pertanian Bogor.

Berman SJ. 2012. Digital transformation: opportunities to create new business model. Strategy and Leadership 40(2):16-24.

Ernies. 2011. Strategi pengembangan teknologi dan inovasi usaha tanaman hias di PT. Saung Mirwan [tesis]. Bogor: Sekolah Pascasarjana, Insitut Pertanian Bogor.

Evi T, Malabay. 2009. Analisis pengembangan aplikasi web untuk profil perusahaan. Seminar Nasional Informatika 1(5): 122-127.

Giesen E. 2010. When and how to innovate your business model. Journal of Strategy and Leadership 38(4):17-26.

Indra ZF. 2017. Strategi pengembangan bisnis tanaman hias CV Green Saujana Nursery [tesis]. Bogor: Sekolah Pascasarjana, Institut Pertanian Bogor.

Kosasi VM. 2015. Analisis dan evaluasi model bisnis pada pantaiseafood restaurant dengan pendekatan business model canvas. Agora 3(1):314-323.

Lamarque E. 2005. Identifiying key activities in bankin firms: acompetence based analysis. Journal of
Emerald Group Publishing Limited. 10(7):2947.

Lozano M, Valles J. 2007. An analysis of the implementation of an environmental management system in a local public administration. Journal of Environmental Management 82(4):495-511.

Mansfield G, Fourie L. 2003. Strategy and business model - a case for convergence and its evolution into strategic architecture. South African Business Management 35(1):35-44.

Nikolao IE, Evangelinos KI. 2010. A SWOT analysis of environmental management practices in greek mining and mineral industry. Resources Policy 53(3):226-234.

Osterwalder A, Pigneur Y. 2010. Business Model Generation. New Jersey: John Wiley \& Sons, Inc.

Osterwalder A, Pigneur Y. 2012. Business Model Generation. Jakarta: PT. Elex Media Komputindo.

Priyono F. 2015. Analisis penerapan business model canvas pada toko moi collection. Agora 3(2):358-363.

Rowley J. 2002. Eight question for customer knowledge management in e-business. Journal of Knowledge Management 6(5):500-511.

Sembiring M. 2013. Analisis model bisnis agrowisata perkebunan teh Gunung Mas, bogor, jawa barat [tesis]. Bogor: Sekolah Pascasarjana, Institut Pertanian Bogor.

Suryanto, Nurhadi. 2003. IPS Ekonomi. Yogyakarta: Erlangga.

Tahernejad H. 2012. A study and effect of brand credibility on word of mouth: with reference to internet service providers in Malaysia. International Journal of Marketing Studies. 4(1):26-37.

Tjiptono F. 2008. Strategi Pemasaran, Ed ke-3. Yogyakarta: ANDI.

Tuten TL, Urban DJ. 2001. An expended model of business to business partnership formation and success. Journal of Industrial Marketing Management 30(2):149-164. 